American Journal of Applied Sciences 7 (4): 568-574, 2010

ISSN 1546-9239

(C) 2010Science Publications

\title{
Evaluating the Maintenance Performance of the Semiconductor Factories Based on the Analytical Hierarchy Process and Grey Relational Analysis
}

\author{
Fei-Long Chen and Yun-Chin Chen \\ Department of Industrial Engineering and Engineering Management, \\ National Tsing Hua University, 101, Section 2, Kuang-Fu Road, \\ Hsinchu, Taiwan 30013, Republic of China
}

\begin{abstract}
Problem statement: Maintenance is an important factor in semiconductor factories, not only because of costs and the need for the uninterrupted operation of semiconductor equipment, but also the time and expense required for maintenance. If maintenance procedures are not performed properly, the equipment will have low efficiency or break down, production capacity will decrease and the company will incur extra costs. Therefore, the evaluation of maintenance performance has become a critical issue in semiconductor industries. Approach: This study evaluated maintenance performance by using the Analytical Hierarchy Process (AHP), Grey Relational Analysis (GRA) and the Technique for Order Preference by Similarity to Ideal Solution (TOPSIS). The weight of maintenance indicators was derived by AHP method, which were input to the GRA and TOPSIS method for evaluate the performance of Condition-Based Maintenance (CBM) and Time-Based Maintenance (TBM) strategies. Results: Actual data was provided by a well-known semiconductor factory in Taiwan. This study evaluated and compared the performance of different maintenance strategies implemented in semiconductor companies. Empirical results indicated that the CBM strategy had better maintenance performance than the TBM strategy in semiconductor companies and the maintenance indicators which should be improved were also identified. Conclusion/Recommendations: The feasibility of the maintenance evaluation method was demonstrated through an actual scenario, which can help managers make decisions objectively and distinguish the advantages and disadvantages of the maintenance strategy.
\end{abstract}

Key words: Maintenance, analytical hierarchy process, grey relational analysis, performance evaluation, semiconductor factories

\section{INTRODUCTION}

Once an equipment or system has been build up, it should be maintained for efficiency and workability. Maintenance program can be regarded as a production sustainable function to prevent the low yield and failure of system. The tendency towards completed automation forces managers to emphasize the evaluation of maintenance performance.

Maintenance plays an important role in semiconductor factories, not only because semiconductor equipment is expensive and needs to operate uninterrupted, but also because the time and expense of maintenance is a great cost for semiconductor factories. If maintenance procedures are not performed properly, the equipment will have low efficiency or break down, production capacity will decrease and the factory will incur extra costs. Therefore, the evaluation of maintenance performance has become an important issue in semiconductor factories. Maintenance performance is difficult to evaluate and depends significantly on various resources in an organization, including the supplement of spare parts and other maintenance materials, manpower, necessary tools and correct instruments and timing for maintenance.

An appropriate evaluation of maintenance performance can help managers improve maintenance efficiency and reduce the costs and risks of system repair. Although the performance evaluation of system maintenance is so important, most studies focus on the scheduling and the cost analysis of maintenance (Yao et al., 2004; Crespo Marquez et al., 2006; Sloan and Shanthikumar, 2002; Camci, 2009; Levin et al.,

Corresponding Author: Yun-Chin Chen, Department of Industrial Engineering and Engineering Management, National Tsing Hua University, 101, Section 2, Kuang-Fu Road, Hsinchu, Taiwan 30013, Republic of China Tel: +886 922201151 Fax: +886 237653639 
2008; Marmier et al., 2009; Aissani et al., 2009; AbiriJahromi et al., 2009; Lee, 2005; Chen and Jin, 2003; Bris et al., 2003; Park and Jung, 2002; Eti et al., 2006; El-Said, 2008). Yao et al. (2004) proposed a mixedinteger programming model for optimal scheduling the preventive maintenance tasks in fabs, which can help manager to eliminate the mistakes and errors. Crespo Marquez et al. (2006) used the Monte Carlo simulation to solve the preventive maintenance scheduling problem in semiconductor fabrication factory. El-Said (2008) analyzed the cost of preventive maintenance by using the Kolmogorov's forward equations. Relatively few studies focus on the performance evaluation of maintenance (Paulsen et al., 1997; Jooste, 2007; Martorell et al., 1999) and studies for the semiconductor industry are even fewer. Paulsen et al. (1997) applied the subsurvival functions to evaluate the maintenance performance of nuclear reactors and the preventive and corrective maintenance failure modes were competed. Jooste (2007) describes the survey of the maintenance performance and achievement in the South African manufacturing industry. Martorell et al. (1999) developed a maintenance evaluation method based on maintenance indicators of the nuclear power plants.

Hence, this study evaluates maintenance performance of semiconductor factories by applying the Analytical Hierarchy Process (AHP), Grey Relational Analysis (GRA) and the Technique for Order Preference by Similarity to Ideal Solution (TOPSIS). Actual data was collected from a well-known semiconductor factory in Taiwan. This study aims to evaluate the performance of Condition-Based Maintenance (CBM) and Time-Based Maintenance (TBM) strategies in semiconductor factory and identifying maintenance indicators which should be improved. The feasibility of the maintenance evaluation method is demonstrated through an actual scenario, which can help managers make decisions objectively and distinguish the advantages and disadvantages of maintenance strategy.

\section{MATERIALS AND METHODS}

This study used the AHP, GRA and the TOPSIS concepts to help managers to make proper decisions in evaluating maintenance performance. This investigation consists of three stages, including (1) the maintenance indicators identification stage, (2) performance evaluation stage and (3) comparison and analysis stage. Figure 1 illustrates the complete structure of this study.

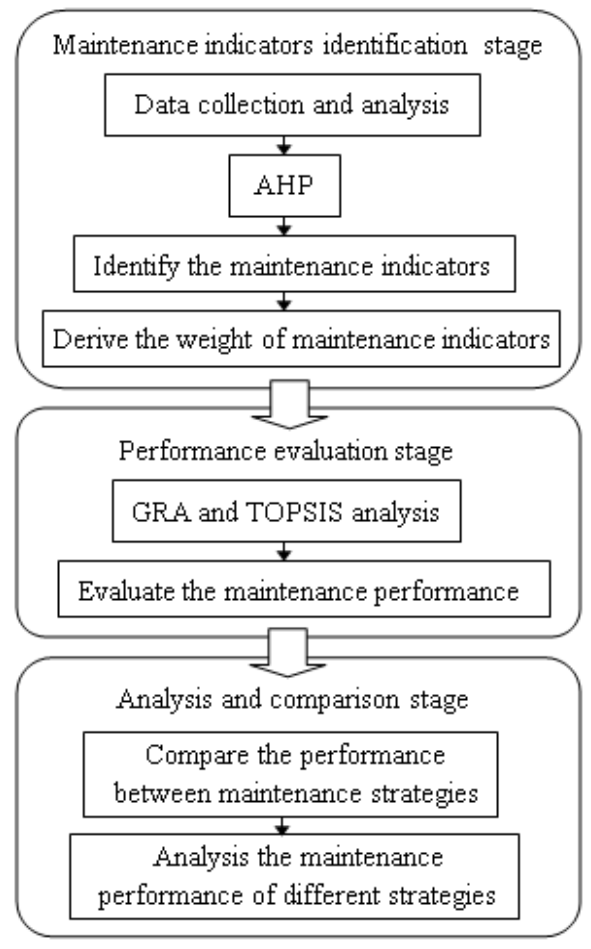

Fig. 1: Structure of this study

Maintenance indicators identification stage: In this stage, the data and information of the maintenance process was collected and the literature on the performance indicators for maintenance management was reviewed. After discussion with experts and the managers of the subject company, the maintenance indicators were selected based on Wireman (2005) research and the AHP method was applied to rank and derive the weights of these maintenance indicators. These indicators then served as the input variables of the GRA and the TOPSIS process in the next stage.

The AHP, which is a decision making method for dealing with complicated, uncertainty and multipleattribute judgment, was developed by Saaty (1990). AHP analyzed the focused problem into several hierarchies, the objective purpose is placed at the top of the hierarchies, and the elements and alternatives are established based on hierarchies. The main procedures of AHP are illustrated as follows (Saaty, 1990).

Develop the overall hierarchical structure of the focused problem: The user must set up the objective and elements to construct the overall hierarchical structure, analyzing the complicated problem into several hierarchies and elements. 
Construct a pairwise comparison matrix and examine its consistency: The evaluators were made pairwise comparisons of the relative importance of elements using the 9-point scale of questionnaire. The pairwise comparison matrix was built based on the results of the questionnaire and the eigenvalue and the eigenvector were derived for checking the consistency of comparison matrix.

The Consistency Ratio (CR) is calculated by the ratio of the Consistency Index (CI) and the Random Index (RI). Equation 1 measures the CI and CR values. The CR should be small than 0.1 to certify consistency and larger values of CR may need the evaluator to check his judgments:

$$
\mathrm{CI}=\frac{\lambda_{\max }-\mathrm{n}}{\mathrm{n}-1}, \quad \mathrm{CR}=\frac{\mathrm{CI}}{\mathrm{RI}}
$$

Where:

$\lambda_{\max }=$ The maximum eigenvalue of the matrix

$\mathrm{n}=$ The size of matrix and the value of RI for corresponding matrix size can be obtained from Saaty (1990) research

Calculate the weights of the elements and the hierarchical levels: After calculating the weights of each element and hierarchy, the user can make a decision based on the significance and weights revealed by the hierarchies and elements.

Performance evaluation stage: Maintenance strategies are generally demarcated into time-based and condition-based maintenance strategies. The TimeBased Maintenance (TBM) strategy is executed at constant time intervals to prevent the failure of machines during operation. The Condition-Based Maintenance (CBM) strategy analyzes the machine condition to determine the timing of maintenance.

The combination of the GRA and the TOPSIS method which was proposed by Chen and Tzeng (2004) was applied to understand and evaluate the maintenance performance of the TBM and CBM strategies, the fivescale was designed for evaluators to identify the performance of the maintenance indicators of the TBM and CBM strategies, and the scale terms from the first to the fifth, are "greatly dissatisfied", "dissatisfied", "fair”, "satisfied”, and "greatly satisfied”, respectively, the weight of maintenance indicators derived by AHP and the statistical results of five-scale forms were then input to the GRA and TOPSIS process for analysis, the main procedures are illustrated as follows (Chen and Tzeng, 2004):
- Calculate the Grey Relational Coefficient (GRC) of the ideal and negative ideal solutions of maintenance performance for the TBM and CBM strategies:

$$
\begin{aligned}
& \gamma\left(A^{+}(j), A_{i}(j)\right)= \\
& \min _{i} \min _{j}\left|A^{+}(j)-A_{i}(j)\right| \\
& \frac{+\zeta \max _{i} \max _{j}\left|A^{+}(j)-A_{i}(j)\right|}{\left|A^{+}(j)-A_{i}(j)\right|} \\
& +\zeta \max _{i} \max _{j}\left|A^{+}(j)-A_{i}(j)\right| \\
& \gamma\left(A^{-}(j), A_{i}(j)\right)= \\
& \min _{i} \min _{j}\left|A^{-}(j)-A_{i}(j)\right| \\
& +\zeta \max _{i} \max _{j}\left|A^{-}(j)-A_{i}(j)\right| \\
& \left|A^{-}(j)-A_{i}(j)\right| \\
& +\zeta \max _{i} \max _{j}\left|A^{-}(j)-A_{i}(j)\right|
\end{aligned}
$$

The mathematical symbol is illustrated as follows (Chen and Tzeng, 2004):

$$
\begin{aligned}
& \gamma\left(\mathrm{A}^{+}(\mathrm{j}), \mathrm{A}_{\mathrm{i}}(\mathrm{j})\right)=\text { The ideal and negative ideal } \\
& \gamma\left(A^{-}(j), A_{i}(j)\right) \text { solutions of the GRC } \\
& \mathrm{A}^{+} \quad=\text { The most superior alternative } \\
& \mathrm{A}^{-} \quad=\text { The most inferior alternative } \\
& \mathrm{i}=\text { The number of alternatives } \\
& \mathrm{j}=\text { The number of evaluation criteria } \\
& \zeta \quad=\text { The discrimination coefficient, } \\
& \text { which was predetermined as } 0.5
\end{aligned}
$$

- Derive the Grey Relational Grade (GRG) of the ideal and the negative ideal solutions of the maintenance performance for the TBM and CBM strategies using the following equations:

$$
\begin{aligned}
& \gamma\left(A^{+}, A_{i}\right)=\sum_{j=1}^{n} w_{j} \gamma\left(A^{+}(j), A_{i}(j)\right) \\
& \gamma\left(A^{-}, A_{i}\right)=\sum_{j=1}^{n} w_{j} \gamma\left(A^{-}(j), A_{i}(j)\right) \\
& \sum_{j=1}^{n} w_{j}=1
\end{aligned}
$$

Where:

$$
\begin{aligned}
\gamma\left(\mathrm{A}^{+}, \mathrm{A}_{\mathrm{i}}\right)= & \text { The ideal and negative ideal } \\
& \text { solutions } \gamma\left(\mathrm{A}^{-}, \mathrm{A}_{\mathrm{i}}\right) \text { of the GRG for each } \\
& \text { alternative, respectively }
\end{aligned}
$$



$\mathrm{w}_{\mathrm{j}}=$ The weight of the maintenance indicators obtained by the AHP method in previous stage
$\mathrm{n}=$ The total number of selected maintenance indicators

- Obtain the relative closeness distance $\left(\mathrm{C}_{\mathrm{i}}\right)$, which measures the closeness of an alternative to the ideal solution, using the following equations (Chen and Tzeng, 2004):

$$
\mathrm{C}_{\mathrm{i}}=\frac{\gamma\left(\mathrm{A}^{+}, \mathrm{A}_{\mathrm{i}}\right)}{\gamma\left(\mathrm{A}^{-}, \mathrm{A}_{\mathrm{i}}\right)}
$$

- Determine the alternative priority according to the $\mathrm{C}_{\mathrm{i}}$ of each alternative, where a higher value of $\mathrm{C}_{\mathrm{i}}$ represents a higher priority of an alternative

After the GRA and TOPSIS analysis process, the performances of the TBM and CBM strategies were evaluated and the performances of maintenance indicators in the strategies were identified. The results of GRA and TOPSIS process are analyzed and compared in the next stage.

Analysis and comparison stage: This stage compares and analyzes the achievement of maintenance indicators and the maintenance performance of different strategies. Using these results, managers can make decisions to improve their maintenance performance.

\section{RESULTS}

This study collected actual data from a famous semiconductor factory in Taiwan. According to the analyzed maintenance data and discussion with experts and the managers of the subject company, the maintenance indicators were identified and their weights were derived by the AHP method. A questionnaire based on AHP was distributed to 37 managers and engineers responsible for maintenance management. After questionnaire collection and analysis through the AHP method, the descriptions and weights of maintenance indicators are shown in Table 1, while Table 2 presents the results of the consistency test.

Based on the result of Table 1, the maintenance indicator with the highest weight is the "the ratio of completed tasks to the scheduled tasks", while the one with the lowest weight is the "total number of rush spare part purchasing orders". The ranking of these maintenance indicators according to importance can help managers evaluate and control maintenance conditions efficiently. Table 2 shows that the CI and the CR of all hierarchy are less than 0.1 , which are acceptable results.

In the subject company, the TBM and CBM strategies were used to maintain production line equipment. The TBM strategy focused on the equipment which can be interrupted during production, whose utility rate was not so high, while the CBM focused on equipment which cannot be interrupted during production, whose utility rate was very high. To better understand the performance of maintenance indicators in the TBM and CBM strategies, the five-scale form was designed based on the maintenance program and distributed to 37 maintenance managers. After these forms were collected and analyzed, the performance evaluation of indicators in the TBM and CBM strategies were derived. Table 3 presents the average value of fivescale form between strategies.

Table 1: Overall weight and ranking of the maintenance indicators

\begin{tabular}{|c|c|c|c|}
\hline Dimension/weight & Maintenance indicator (monthly) & $\begin{array}{l}\text { Overall } \\
\text { weight }\end{array}$ & Ranking \\
\hline $\begin{array}{l}\text { Preventive maintenance } \\
\text { Pan }\end{array}$ & The ratio of completed tasks to the scheduled tasks & 0.3831 & 1 \\
\hline 0.4894 & The ratio of breakdowns caused by items that should be inspected to the total number of breakdowns & 0.1063 & 2 \\
\hline Spare parts inventory & Dollar amount of spare part usage & 0.0480 & 5 \\
\hline \multirow[t]{3}{*}{ and procurement 0.1274} & Total number of the spare part purchasing orders not filled on demand & 0.0481 & 4 \\
\hline & Total number of the spare part purchasing orders filled on demand & 0.0201 & 13 \\
\hline & Total number of rush spare part purchasing orders & 0.0112 & 17 \\
\hline \multirow{6}{*}{$\begin{array}{l}\text { Maintenance planning } \\
\text { and scheduling } 0.1757\end{array}$} & Total number of planned maintenance work order & 0.0444 & 6 \\
\hline & Total scheduled hours of maintenance work. & 0.0320 & 10 \\
\hline & Total hours estimated on scheduled maintenance work orders & 0.0245 & 12 \\
\hline & Total number of completed maintenance work order & 0.0380 & 8 \\
\hline & Total number of completed maintenance work order that exceeding the estimated material cost & 0.0183 & 15 \\
\hline & Total number of overdue maintenance work order & 0.0186 & 14 \\
\hline \multirow{3}{*}{$\begin{array}{l}\text { Maintenance operational } \\
\text { involvement } 0.1090\end{array}$} & Total hours of equipment repair & 0.0424 & 7 \\
\hline & Total hours of actual maintenance work & 0.0366 & 9 \\
\hline & Total hours of preventive maintenance work & 0.0300 & 11 \\
\hline \multirow{2}{*}{$\begin{array}{l}\text { The reliability of } \\
\text { maintenance } 0.0985\end{array}$} & Number of equipment breakdowns & 0.0807 & 3 \\
\hline & Number of repetitive equipment failures & 0.0177 & 16 \\
\hline
\end{tabular}


Am. J. Applied Sci., 7 (4): 568-574, 2010

Afterwards, the weights of maintenance indicators derived by AHP were substituted into the combination of GRA and TOPSIS method, and the GRC of the ideal and negative ideal solutions of the indicators were calculated. Table 4 presents the GRC of the maintenance strategies.

Table 4 presents the indicator performance of maintenance strategies after considering the weights of indicators. According to the Table 4, we can easily evaluate and compare the performance of the TBM and CBM strategies.

The closer to 1 of GRC in ideal solution, the better performance of the indicator shows. The closer to 1 of GRC in negative ideal solution, the worse performance of the indicator presents. Therefore, TBM strategy has better performance in "total number of planned maintenance work order" than other indicators, while the CBM strategy has better performance in "total number of rush spare part purchasing orders" and "total hours estimated on scheduled maintenance work orders" than other indicators. The indicator which both strategies must improve is "total hours of preventive maintenance work", which means that the scheduling and the time control of preventative maintenance work should be improved. The evaluators can compare the performance of each indicator between maintenance strategies. The ideal solutions of the CBM strategy are mostly greater than those of the TBM strategy and the negative ideal solutions of the CBM strategy mostly smaller than those of the TBM strategy.

In addition, the GRG and the relative closeness distance of the TBM and CBM strategies were also derived, as shown in Table 5.
Table 5 shows that the 1.2143 of CBM is greater than the 0.9677 of TBM in the relative closeness distance, which indicates that the CBM strategy has better overall maintenance performance than the TBM strategy.

Table 2: Consistency test result of the hierarchy

\begin{tabular}{lll}
\hline Examined dimension & CI & CR \\
\hline Preventive maintenance & 0.0000 & 0.0000 \\
Spare parts inventory and procurement & 0.0875 & 0.0972 \\
Maintenance planning and scheduling & 0.0991 & 0.0799 \\
Maintenance operational involvement & 0.0171 & 0.0295 \\
The reliability of maintenance & 0.0000 & 0.0000 \\
\hline
\end{tabular}

Table 3: The average value of five-scale form between strategies

\begin{tabular}{|c|c|c|}
\hline \multirow[b]{2}{*}{ Maintenance indicators } & \multicolumn{2}{|c|}{ Maintenance strategy } \\
\hline & TBM & CBM \\
\hline The ratio of completed tasks to the scheduled tasks & 3.7838 & 3.7568 \\
\hline $\begin{array}{l}\text { The ratio of breakdowns caused by items that should } \\
\text { be inspected to the total number of breakdowns }\end{array}$ & 3.4324 & 3.4595 \\
\hline Dollar amount of spare part usage & 3.5676 & 3.4865 \\
\hline $\begin{array}{l}\text { Total number of the spare part purchasing orders } \\
\text { not filled on demand }\end{array}$ & 3.4054 & 3.3514 \\
\hline $\begin{array}{l}\text { Total number of the spare part purchasing orders } \\
\text { filled on demand }\end{array}$ & 3.8378 & 3.5676 \\
\hline Total number of rush spare part purchasing orders & 3.7297 & 3.8108 \\
\hline Total number of planned maintenance work order & 4.0541 & 3.5135 \\
\hline Total scheduled hours of maintenance work. & 3.8649 & 3.6216 \\
\hline $\begin{array}{l}\text { Total hours estimated on scheduled maintenance } \\
\text { work orders }\end{array}$ & 3.7568 & 3.8108 \\
\hline Total number of completed maintenance work order & 3.7838 & 3.5676 \\
\hline $\begin{array}{l}\text { Total number of completed maintenance work order } \\
\text { that exceeding the estimated material cost }\end{array}$ & 3.7838 & 3.7027 \\
\hline Total number of overdue maintenance work order & 3.7027 & 3.3514 \\
\hline Total hours of equipment repair & 3.7568 & 3.5946 \\
\hline Total hours of actual maintenance work & 3.0811 & 3.1622 \\
\hline Total hours of preventive maintenance work & 3.0000 & 2.5676 \\
\hline Number of equipment breakdowns & 3.1351 & 3.4054 \\
\hline Number of repetitive equipment failures & 3.2432 & 3.5676 \\
\hline
\end{tabular}

\begin{tabular}{|c|c|c|c|c|}
\hline \multirow[b]{3}{*}{ Maintenance indicators } & \multicolumn{4}{|c|}{ Maintenance strategy } \\
\hline & \multicolumn{2}{|l|}{ TBM } & \multicolumn{2}{|l|}{ CBM } \\
\hline & Ideal solution & $\begin{array}{l}\text { Negative ideal } \\
\text { solution }\end{array}$ & Ideal solution & $\begin{array}{l}\text { Negative ideal } \\
\text { solution }\end{array}$ \\
\hline The ratio of completed tasks to the scheduled tasks & 0.8780 & 0.8182 & 0.9780 & 0.7143 \\
\hline $\begin{array}{l}\text { The ratio of breakdowns caused by items that have should be inspected to } \\
\text { the total number of breakdowns }\end{array}$ & 0.7579 & 0.8908 & 0.8725 & 0.7692 \\
\hline Dollar amount of spare part usage & 0.8000 & 0.8614 & 0.8812 & 0.7639 \\
\hline Total number of the spare part purchasing orders not filled on demand & 0.7500 & 0.8969 & 0.8396 & 0.7914 \\
\hline Total number of the spare part purchasing orders filled on demand & 0.9000 & 0.8080 & 0.9082 & 0.7483 \\
\hline Total number of rush spare part purchasing orders & 0.8571 & 0.8286 & 1.0000 & 0.7051 \\
\hline Total number of planned maintenance work order & 1.0000 & 0.7699 & 0.8900 & 0.7586 \\
\hline Total scheduled hours of maintenance work. & 0.9114 & 0.8031 & 0.9271 & 0.7383 \\
\hline Total hours estimated on scheduled maintenance work orders & 0.8675 & 0.8233 & 1.0000 & 0.7051 \\
\hline Total number of completed maintenance work order & 0.8780 & 0.8182 & 0.9082 & 0.7483 \\
\hline $\begin{array}{l}\text { Total number of completed maintenance work order that exceeding the } \\
\text { estimated material cost }\end{array}$ & 0.8780 & 0.8182 & 0.9570 & 0.7237 \\
\hline Total number of overdue maintenance work order & 0.8471 & 0.8339 & 0.8396 & 0.7914 \\
\hline Total hours of equipment repair & 0.8675 & 0.8233 & 0.9175 & 0.7432 \\
\hline Total hours of actual maintenance work & 0.6667 & 0.9775 & 0.7876 & 0.8333 \\
\hline Total hours of preventive maintenance work & 0.6486 & 1.0000 & 0.6593 & 1.0000 \\
\hline Number of equipment breakdowns & 0.6792 & 0.9631 & 0.8558 & 0.7801 \\
\hline Number of repetitive equipment failures & 0.7059 & 0.9355 & 0.9082 & 0.7483 \\
\hline
\end{tabular}


Table 5: The GRG and relative closeness distance of the maintenance strategies

\begin{tabular}{|c|c|c|c|c|}
\hline \multirow[b]{2}{*}{$\begin{array}{l}\text { Maintenance } \\
\text { strategy }\end{array}$} & \multicolumn{2}{|l|}{ TBM } & \multicolumn{2}{|l|}{ CBM } \\
\hline & $\begin{array}{l}\text { Ideal } \\
\text { solution }\end{array}$ & $\begin{array}{l}\text { Negative ideal } \\
\text { solution }\end{array}$ & $\begin{array}{l}\text { Ideal } \\
\text { solution }\end{array}$ & $\begin{array}{l}\text { Negative ideal } \\
\text { solution }\end{array}$ \\
\hline$\overline{\text { GRG }}$ & $\begin{array}{l}0.8271 \\
\end{array}$ & 0.8547 & 0.9135 & 0.7523 \\
\hline $\begin{array}{l}\text { Relative closeness } \\
\text { distance }\left(\mathrm{C}_{\mathrm{i}}\right)\end{array}$ & 0.9677 & & 1.2143 & \\
\hline
\end{tabular}

\section{DISCUSSION}

The performance of the TBM and CBM strategies has rarely been evaluated in the semiconductor factory using maintenance indicators. Therefore, this study evaluates and compares the maintenance performance of both strategies and identifies the important maintenance indicators and the ranking of these indicators in semiconductor factories.

However, when the GRC of the ideal solution is relative close to the negative ideal solution, it might be difficult for decision-makers to evaluate the maintenance performance of each indicator. Therefore, future research could focus on a solution to this problem.

Empirical results indicate that the CBM strategy has better maintenance performance than the TBM strategy for semiconductor companies, suggesting that critical equipment or systems can apply to the CBM strategy to ensure maintenance reliability and reduce the risk and the semiconductor factories. This study also identifies which indicators should be improved in the TBM and CBM strategies, allowing managers to focus on these indicators to improve their maintenance performance.

\section{CONCLUSION}

This study applies the AHP, GRA and TOPSIS methods to evaluate the maintenance performance between TBM and CBM strategies. Before this study, few research focus on the performance evaluation of maintenance strategies in the semiconductor factory.

Actual data was collected from a famous semiconductor factory in Taiwan. Empirical results indicate that the CBM strategy has better maintenance performance than the TBM strategy for semiconductor companies and the maintenance indicators which should be improved of both strategies were also identified. The feasibility and the efficiency of the maintenance evaluation method were demonstrated through a real scenario.

\section{REFERENCES}

Abiri-Jahromi, A., M. Fotuhi-Firuzabad and E. Abbasi, 2009. An efficient mixed-integer linear formulation for long-term overhead lines maintenance scheduling in power distribution systems. IEEE Trans. Power Deliv., 24: 2043-2053. DOI:10.1109/TPWRD.2009.2028785

Aissani, N., B. Beldjilali and D. Trentesaux, 2009. Dynamic scheduling of maintenance tasks in the petroleum industry: A reinforcement approach. Eng. Applied Artif. Intell., 22: 1089-1103. DOI: 10.1016/j.engappai.2009.01.014

Bris, R., E. Chatelet and F. Yalaoui, 2003. New method to minimize the preventive maintenance cost of series-parallel systems. Reliab. Eng. Syst. Safe., 82: 247-255. DOI: 10.1016/S0951-8320(03)00166-2

Camci, F., 2009. System maintenance scheduling with prognostics information using genetic algorithm. IEEE Trans. Reliab., 58: 539-552. DOI: 10.1109/TR.2009.2026818

Chen, M.F. and G.H. Tzeng, 2004. Combining grey relation and TOPSIS concepts for selecting an expatriate host country. Math. Comput. Model., 40: 1473-1490. DOI: 10.1016/j.mcm.2005.01.006

Chen, Y. and J. Jin, 2003. Cost-variability-sensitive preventive maintenance considering management risk. IIE Trans., 35: 1091-1101. DOI: 10.1080/07408170390237162

Crespo Marquez, A., J.N.D. Gupta and J.P. Ignizio, 2006. Improving preventive maintenance scheduling in semiconductor fabrication facilities. Prod. Plan. Control, 17: 742-754. DOI: 10.1080/09537280600901525

El-Said, K.M., 2008. Cost analysis of a system with preventive maintenance by using the Kolmogorov's forward equations method. Am. J. Applied Sci., 5: 405-410.

http://www.scipub.org/fulltext/ajas/ajas54405-410.pdf

Eti, M.C., S.O.T. Ogaji and S.D. Probert, 2006. Reducing the cost of Preventive Maintenance (PM) through adopting a proactive reliability-focused culture. Applied Energy, 83: 1235-1248. DOI: 10.1016/j.apenergy.2006.01.002

Jooste, J.L., 2007. Maintenance performance in the South African industry. South Afr. J. Ind. Eng., 18: 117-133. http://proquest.umi.com.nthuliboc.nthu.edu.tw/pqdweb?did=1368809181\&sid=1\& Fmt $=3 \&$ clientId $=39468 \&$ RQT $=309 \&$ VName=PQD

Lee, H.H., 2005. A cost/benefit model for investments in inventory and preventive maintenance in an imperfect production system. Comput. Ind. Eng., 48: 55-68. DOI: 10.1016/j.cie.2004.07.008 
Levin, A., G. Mosheiov and A. Sarig, 2008. Scheduling a maintenance activity on parallel identical machines. Nav. Res. Logist., 56: 33-41. DOI: 10.1002/nav.20324

Marmier, F., C. Varnier and N. Zerhouni, 2009. Proactive, dynamic and multi-criteria scheduling of maintenance activities. Int. J. Prod. Res., 47: 2185-2201. DOI: 10.1080/00207540802311106

Martorell, S., A. Sanchez, A. Munoz, J.L. Pitarch and V. Serradell et al., 1999. The use of maintenance indicators to evaluate the effects of maintenance programs on NPP performance and safety. Reliab. Eng. Syst. Safe., 65: 85-94. http://sdos.ejournal.ascc.net.nthuliboc.nthu.edu.tw/pdflinks/10011222493914346.pdf

Park, D.H. and G.M. Jung, 2002. Preventive maintenance policy with effect dependent cost. Asia Pac. J. Operat. Res., 19: 223-232. http://www.encyclopedia.com/doc/1P3-295673851.html

Paulsen, J., R. Cooke and R. Nyman, 1997. Comparative evaluation of maintenance performance using subsurvival functions. Reliab. Eng. Syst. Safe., 58: 157-163. DOI: 10.1016/S0951-8320(97)00036-7
Saaty, T.L., 1990. How to make a decision: The analytic hierarchy process. Eur. J. Oper. Res., 48: 9-26. DOI: 10.1016/0377-2217(90)90057-I

Sloan, T.W. and J.G. Shanthikumar, 2002. Using in-line equipment condition and yield information for maintenance scheduling and dispatching in semiconductor wafer fabs. IIE Trans., 34: 191-209. DOI: 10.1023/A:1011900215443

Wireman, T., 2005. Developing Performance Indicators for Managing Maintenance. 2nd Edn., Industrial Press Inc., New York, ISBN: 9780831132446, pp: 250.

Yao, X.D., E. Fernandez-Gaucherand, M.C. Fu and S.I. Marcus, 2004. Optimal preventive maintenance scheduling in semiconductor manufacturing. IEEE Trans. Semicond. Manuf., 17: 345-356. DOI: 10.1109/tsm.2004.831948 